\title{
Comer como um passarinho, cozinhar como uma feiticeira: a herança edênica na construção da relação entre gênero e comida*
}

\section{Wanessa Asfora ${ }^{* *}$}

Donne e cibo. Uma relazione nella storia, de Maria Giuseppina Muzzarelli e Fiorenza Tarozzi, apresenta um panorama acerca da relação entre mulheres e comida ao longo da história ocidental, mais especificamente a partir da Idade Média. De caráter sintético - de fato, a obra pertence à coleção Sintesi da editora Bruno Mondadori -, está dividida em duas partes que refletem as especialidades de suas autoras: a primeira, "A Idade Média e a Idade Moderna", foi escrita por Maria Giuseppina Muzzarelli, historiadora e professora de História Medieval na Faculdade de Letras e Filosofia da Universidade de Bologna; e a segunda, intitulada "A sociedade contemporânea", é de autoria de Fiorenza Tarozzi, também historiadora, que ensina História Contemporânea na Faculdade de Língua e Literatura Estrangeira da mesma universidade.

Os temas abordados em dezoito breves capítulos estão organizados em torno da investigação dos processos históricos que levaram ao estabelecimento dos ideais de comportamento feminino diante da alimentação. De maneira geral, pode-se dizer que a questão central da obra diz respeito à mulher frente à gestão adequada da comida, seja ela para si própria, seja ela para os outros. Logo na Introdução, M. G. Muzzarelli e F. Tarozzi

\footnotetext{
* Resenha de Muzzarelli, Maria Giuseppina; TARozzi, Francesca. Donne e cibo. Una relazione nella storia. Milão, Bruno Mondadori, 2003. Recebida para publicação em 07 de março de 2012, aceita em 15 de março de 2012.

** Doutora em História Medieval pela Universidade de São Paulo. wanessaasfora@usp.br
}

cadernos pagu (39), julho-dezembro de 2012:431-445. 
evidenciam um aspecto decorrente dessa questão que talvez seja, de todos aqueles investigados na obra, aquele que mais instiga as autoras: o enraizamento da associação entre mulheres e consumo de pouca quantidade de comida, afinal "A mulher que se alimenta como um passarinho constituiu por séculos o modelo de referimento feminino presente na mente dos homens" (p. VIII). As autoras indagam por que razões essa associação se constrói $e$ permanece interiorizada ao longo de tantos séculos:

por supostas razões objetivas, já que [as mulheres] se dedicaram, em geral, a trabalhos menos pesados nos quais gastavam menor número de calorias, ou por motivos culturais que fincavam raízes em teorias e preconceitos de séculos longínquos? (p. VIII).

Fazendo uma clara opção pelo papel da cultura e não da biologia na modelagem dos comportamentos alimentares, o livro propõe investigar, a partir da análise de fontes escritas $e$ iconográficas, não apenas as ditas raízes, mas igualmente a mentalidade que lhe faz fundo. $\mathrm{O}$ quadro explicativo começa a se delinear na própria Introdução quando as historiadoras afirmam que os motivos do pouco consumo de alimentos associado às mulheres fundamentam-se em razões masculinas ancoradas no ideário cristão sobre os pecados capitais que propunha que todos os vícios nasciam da gula e que a continentia exigida das mulheres no campo sexual encontrava um pressuposto indispensável na abstinentia alimentar. Fundamentos que nos remetem, necessariamente, ao modelo bíblico feminino, personificado na figura de Eva. Residiria, assim, na mulher primordial, as raízes da configuração de um ideal de comportamento alimentar feminino que só irá sofrer transformações significativas, segundo as autoras, a partir do final do século XX, com o estabelecimento de um discurso que prega posturas alimentares mais equânimes (se não na prática, pelo menos em teoria) entre homens e mulheres. 
Não sem razão, o ponto de partida da obra é a Idade Média, momento em que estudos das escrituras bíblicas e, em particular, do episódio fundante do pecado original cometido no Paraíso conformarão interpretações duradouras acerca do destino da humanidade e do papel do homem e da mulher na sociedade ocidental. Na leitura de M. G. Muzzarelli, as figuras femininas da Antiguidade são obscurecidas por Eva, a grande responsável, pelo menos a partir do século $\mathrm{XV}$, pelo ato guloso que conduziu a humanidade à ruína. Por sua falta, homens e mulheres levarão uma existência maculada e condenada para sempre a uma incessante busca da salvação. A ponderação cronológica oferecida no primeiro capítulo é de grande importância para que se compreenda como certas noções são construídas historicamente. A atribuição do pecado somente à figura feminina personificada em Eva é resultante de um processo histórico tecido ao longo dos primeiros tempos da Idade Média e não um dado imediatamente estabelecido.

Segundo as primeiras interpretações de alguns exegetas cristãos, coube tanto a Eva quanto a Adão a responsabilidade pelo ato pecaminoso; pecado este inicialmente entendido como da soberba e não propriamente da gula - o fruto proibido teria sido apenas um veículo para a prática de um ato de natureza mais perniciosa, a crença orgulhosa na possibilidade do homem transgredir, por vontade própria, os desígnios divinos. De forma geral, a grande preocupação ao longo do período medieval é com o controle do desejo e do prazer. Comportamentos incontinentes rompiam com a ordem divina do cosmos e deveriam ser freados através de uma série de práticas ascéticas moderadas (preces, abstinências e jejuns) ou radicais (mortificações corporais extremas como aquelas performatizadas por santas e místicas do período). O objetivo, tanto de homens quanto de mulheres, era a condução de uma vida calcada na justa medida. Não é à toa que por tanto tempo o fruto proibido foi carregado de ambiguidades - seria ele veículo ou motor do pecado? seria ele maçã, figo, marmelo ou romã? A existência de debate acerca desses temas indicaria, muito 
provavelmente, um não enrijecimento da associação única $e$ nefasta entre mulher, comida e pecado.

Será então apenas no final da Idade Média que se consolidará uma ideia que perdurará por muitos séculos: é a mulher (Eva), movida pelo desejo, que induz o homem (Adão) ao pecado através do convite sedutor para o consumo de uma iguaria. No Barroco, essa ideia já terá se tornado uma obsessão. Astúcia, vileza, irracionalidade, sedução e outros atributos considerados moralmente negativos, passam a ser entendidos como "naturais" da condição feminina herdada daquela Eva. É igualmente por seu pecado que a harmonia edênica foi rompida $e$ que a existência de homens e mulheres, expulsos do Paraíso, passou a ser constantemente ameaçada, dentre outras coisas, pela fome e pela doença. Suprir essas carências, através do abastecimento alimentar da casa, da nutrição da família e do cuidado de doentes, tornou-se parte da herança deixada por Eva a todas as mulheres. Com isso, as historiadoras estabelecem o grande pano de fundo mental sobre o qual uma série de outras problemáticas ligadas à associação entre mulher e comida deve ser percebida.

É o caso do deslizamento associativo que vai se processando lentamente entre a incumbência herdada pela mulher de cuidar da casa com a capacidade de utilizar esses saberes, especialmente o culinário, para a confecção de poções, filtros, mezinhas e outras preparações culinárias utilizadas como artimanhas para conseguir atender desejos e caprichos junto aos homens. Essa aproximação "natural" entre o sexo feminino e a magia ganha contornos mais estabelecidos nos séculos XII e XIII, quando a profissionalização do medicus (posição essencialmente masculina), relega as curandeiras ao espaço marginal ocupado por bruxas e feiticeiras. No século XV, a associação estará fortemente estabelecida.

Além da especialização na manipulação culinária, o grupo das feiticeiras poderia comportar também mulheres adeptas a jejuns extremados. $\mathrm{O}$ hábito de recusar a comida até o limite da 
inanição, observado dentre algumas mulheres, particularmente santas, monjas e místicas, revelava-se tão suspeito quanto às práticas mágicas. M. G. Muzzarelli, alinhando-se à tese da historiadora Caroline Walker Bynum - que inaugurou em Holy Feast, Holy Fast, uma nova proposta de entendimento dos comportamentos alimentares das chamadas santas jejuadoras da Idade Média (Bynum, 1987) - acredita que tal comportamento alimentar não significava fuga diante do papel social limitado $e$ pouco valorizado relegado às mulheres $\mathrm{da}$ sociedade baixomedieval e do início do período moderno. Muito pelo contrário, representava um tipo de estratégia para conquistar espaço, expressar vontade própria e acessar o divino - algo que lhes era frequentemente negado em outros setores da vida pública. Dessa maneira, Muzzarelli posiciona-se resistente à tese de Rudolph Bell - outra importante interpretação acerca do entendimento histórico-cultural dos distúrbios alimentares (Bell, 1985) - que em Holy Anorexia enxerga uma linha contínua e um mesmo mecanismo psicológico entre o comportamento daquelas mulheres jejuadoras $e$ as anoréxicas da contemporaneidade. Para a historiadora, a relação entre mulheres e comida é dinâmica e referendada por condições sociais próprias aos diferentes contextos históricos que devem ser compreendidos em suas especificidades. ${ }^{1}$

A crença no pertencimento quase atávico das mulheres ao universo alimentar confere ainda outras associações interessantes de serem discutidas. M. G. Muzzarelli investiga, por exemplo, se haveria uma comida de natureza essencialmente feminina, $e$ encontra dificuldade nesse terreno, pois o que é possível vislumbrar, através da documentação utilizada, é apenas a existência de comidas relacionadas a etapas da vida da mulher (como o puerpério e a amamentação) ou de certas atividades

\footnotetext{
1 Ver o artigo de Carole Counihan traduzido neste dossiê que traz uma comparação interessante entre as mencionadas obras de Caroline Walker Bynum e Rudolph Bell, posicionando-as criticamente no debate antropológico sobre distúrbios alimentares femininos do final da década de 1980.
} 
culinárias consideradas tipicamente femininas. Deste último grupo, fazem parte aquelas ligadas ao uso do forno (preparar e assar o pão e massas, de maneira geral) e os cuidados da horta. Relevante notar que se tratam de atividades de âmbito doméstico. A cozinha de casa, com todas as tarefas necessárias para seu funcionamento (abastecimento, preparo da comida e limpeza), é reduto da mulher, enquanto a cozinha de corte e das grandes casas burguesas, a cozinha aberta ao público, poder-se-ia dizer, é espaço de homens, como tantos que deixaram seus nomes atrelados a livros de cozinha e manuais de gestão doméstica.

A primeira parte da obra encerra-se com um breve balanço acerca de como (e quais) aspectos da relação entre mulher $e$ comida abordados anteriormente foram se transformando com o adentrar dos primeiros séculos do período moderno. É o que acontecerá, por exemplo, com o posicionamento de mulheres pertencentes aos grupos aristocráticos diante da amamentação. Entre os séculos XVII e XVIII, uma nova configuração familiar está em jogo e traz repercussões diretas no recurso, até então bastante usual, a amas de leite para a função de nutrir recém-nascidos. Outra mudança apontada é a possibilidade, a partir do século XVIII, do exercício do ofício público de cozinheiro conferida às mulheres - processo lento e gradativo que não se dá, obviamente, sem resistência a velhos preconceitos. Aliás, alguns deles, como a não adequação da mulher para uma educação cívica e pública, persistirão e continuarão a limitar, até muito recentemente, a circulação feminina aos espaços domésticos.

Da maneira como a obra é tecida, fica claro que as problemáticas relacionadas às mulheres e à comida na contemporaneidade estão postas desde a Idade Média. No entanto, é importante lembrar que, embora se tratem de problemáticas antigas, estas devem ser reconhecidas como parte de processos históricos que vão apresentando traços diferenciados à medida que novas configurações da sociedade são estabelecidas. Assim, na segunda parte, a questão central da obra é retomada à luz das transformações culturais, sociais $e$ 
econômicas que se processam a partir do século XVIII - para as autoras, sem dúvida alguma, o ponto de inflexão (e às vezes até de ruptura) entre modelos distintos de comportamento da mulher diante da alimentação, seja ele administrando a comida para si, seja gerindo-a para os outros.

Aprender a gerir a alimentação do outro é parte da agenda educacional feminina que acontece dentro de casa de maneira bastante informal e oralizada através da figura materna. É ela que irá transmitir às filhas as virtudes que deve ter uma boa mulher. Em termos práticos, iss se traduz principalmente em tarefas como a provisão de comida à família (amamentação, abastecimento de alimentos e preparo culinário) e o cuidado com filhos e doentes (inclusive com a administração de medicamentos feitos à base de ingredientes também culinários). A partir do século XVIII, porém, esse processo de aprendizagem tradicional e doméstico sofrerá modificações significativas. Nesse sentido, F. Tarozzi aponta o papel representativo dos manuais de boas maneiras na tarefa de oferecer uma educação virtuosa às mulheres. Assim, somavam-se ao domínio das tarefas do lar, saberes ligados ao convívio público (ainda restrito, mas não mais de todo inexistente): saber com quem comer, quando comer, como comer e, acima de tudo, quanto comer. Os manuais recomendam claramente que a mulher coma pouco, uma vez que mostrar apetite voraz era sinal de má educação, inaptidão social e falta de bom gosto, noção importante para a época (Flandrin,1991:267-309).

Mais tarde, já no século XX, entrarão em cena outros elementos. F. Tarozzi lembra como as tarefas domésticas mudam de estatuto com o advento da Economia Doméstica, "ciência" que incorporava princípios da revolução industrial e tecnológica em curso desde o século XIX, como, por exemplo, o taylorismo e as teorias higienistas. A administração da casa, que tem na cozinha seu "headquarter", passa a ser orientada por noções novas amparadas pelo conhecimento laico e científico da época: eficiência, economia, limpeza e higiene. Afora isso, o aprendizado dessa ciência não acontece nos espaços domésticos tradicionais, 
escolas destinadas a ensinar formalmente Economia Doméstica foram fundadas em países europeus como a França e a Alemanha. Na esteira dessas transformações na organização da vida doméstica, estão os eletrodomésticos (geladeiras, fogão a gás, lava roupas, etc.) e todas as inovações da indústria alimentícia (alimentos prontos, conservas, enlatados, entre outros) com vistas a diminuir o tempo gasto com abastecimento e preparo dos alimentos pela mulher que começa a trabalhar fora de casa com muito mais frequência.

No entanto, a despeito dessa "profissionalização" das tarefas domésticas e do fato, inegável, de que a mulher moderna passa a ocupar, a partir do final do século XIX e ao longo do século XX, cada vez mais espaço na vida pública, F. Tarozzi reconhece a resistência de uma ideia longínqua, aquela que posiciona a mulher em um locus considerado "natural": a cozinha com todas as atribuições que dela decorrem. Talvez esse aspecto tenha reforçado a ínfima participação da mulher no exercício da profissão de chefe de cozinha, pois mesmo quando a ela é chancelada maior participação na vida pública e profissional, os ofícios de cozinha não constituem prioridades na escolha de suas carreiras. A cozinha profissional, bem como a escrita de livros de receitas, permanece sendo um reduto quase exclusivo de homens até o final do século XX. Ora, trata-se, como mostra Tarozzi, de desafiar uma condição herdada e carregada por séculos. Desafio que integra um processo que remonta aos séculos medievais, como indicou na primeira parte M. G. Mussarelli, mas que no século XX revelava diferentes motivações. Maternidade, família e vida doméstica deixaram de encabeçar o rol das aspirações usuais de gerações de mulheres mais jovens. Ao invés disso, em seu lugar, encontram-se a carreira e o cuidado de si em uma extensão jamais vista até então.

Os dois últimos capítulos do livro são especialmente dedicados ao cuidado de si. A discussão passa necessariamente pela alimentação e esta, por sua vez, quando diz respeito à mulher, insere-se em um enquadramento teórico mais amplo no 
qual a instituição de cânones para o corpo feminino e de padrões de beleza ocupa lugar central. O tema, já tratado na primeira parte da obra, retorna pela força que adquire na contemporaneidade. São claras as transformações ao longo dos séculos: da magreza etérea e santificada da Idade Média passa-se a valorizar corpos mais arredondados no período moderno - ainda que a verdadeira apreciação recaísse sempre pela boa proporção e não pelo excesso de gordura - chegando à magreza símbolo de beleza e saúde das mulheres dos séculos XIX e XX, respectivamente.

$\mathrm{Na}$ realidade, no século XIX convivem dois modelos de referimento para o corpo da mulher: o modelo da classe trabalhadora, chamado por F. Tarozzi de "popular", que valorizava a saúde e a força produtiva e reprodutiva de corpos mais robustos; e o modelo "aristocrático-burguês" calcado em padrões estéticos rígidos que preconizavam um corpo diáfano e longilíneo como de uma eterna adolescente, alcançável através de dietas e do uso do espartilho. O século XX assistirá a disseminação do modelo aristocrático-burguês e sua gradativa, ainda que desigual, incorporação por mulheres de todas as classes sociais. Incorporação consciente ou inconsciente, mas, de qualquer maneira, fortemente impulsionada, de um lado, pela indústria de cosméticos e prestadores de serviço de estética $e$ beleza, e de outro, pelo discurso médico que cada vez mais passa a associar gordura à doença. Se saúde tem a ver com magreza, esta, por sua vez, vem colocando problemas de interpretação, oscilando subjetivamente entre as noções de equilíbrio e de excesso. Tarozzi posicionará aí o debate sobre os distúrbios alimentares do século XX.

As motivações que levaram as mulheres desses dois últimos séculos a controlar a quantidade de comida consumida com vistas a atingir corpos com variadas gradações de magreza são claramente distintas. A discussão aprofundada de tais motivações não parece ser do interesse de F. Tarozzi; por outro lado, a historiadora oferece uma rica contribuição ao reforçar que a comida, por se apresentar na história das mulheres como o único 
terreno considerado legitimamente feminino, acabou funcionando como campo privilegiado de manobras e estratégias para o enfrentamento de situações desfavoráveis pelas quais passaram as mulheres através dos séculos.

\section{A questão do gênero}

Entender a comida como campo de combate é um ponto de partida inovador para os estudos que pretendem se dedicar à relação entre mulheres e comida ao longo da história ocidental. Apresentar essa perspectiva teórica e seu compartilhamento por outros especialistas mencionados em notas de rodapé revela-se o aspecto mais enriquecedor da obra de M. G. Muzzarelli e F. Tarozzi. Essa razão, por si só, já bastaria para a leitura da obra. Soma-se a ela também a disponibilização de uma bibliografia específica sobre o tema, em geral, pouquíssimo conhecida dos leitores brasileiros. Uma tradução para o português seria mais do que bem-vinda; ainda mais se considerarmos a escassez de estudos que tocam, mesmo que indiretamente, a discussão sobre comida e gênero.

Nesse sentido, aliás, vale à pena tecer algumas considerações. A rigor, Donna e cibo não é uma obra que se enquadre propriamente na categoria de estudos das relações de gênero. Seria mais apropriado dizer que se trata de uma obra sobre história das mulheres, uma vez que discorre sobre experiências diversas, no que diz respeito à comida, vivenciadas por mulheres de grupos sociais distintos entre a Idade Média e a contemporaneidade. Para as historiadoras, "gênero" não constitui uma categoria de análise (García, 2006), e a oscilação entre o uso de termos como "feminino", "masculino", "homem" $e$ "mulher" acontece de maneira indiferenciada ao longo de todos os capítulos - aspecto que não pode ser considerado um problema, uma vez que as autoras não afirmam estar fazendo um estudo das relações de gênero. 
No entanto, se as pesquisas que se inserem dentro dos estudos de gênero

\begin{abstract}
visam [...] não descrever como viviam as mulheres ou como essas se relacionavam com os homens no passado, mas analisar e explicar os sistemas de significação [grifos meus] das diferenças sexuais (Silva, 2009:99),
\end{abstract}

é admissível perceber algo das relações de gênero na obra de Muzzarelli e Tarozzi. E isso é possível, particularmente, na primeira parte do livro, quando se apresenta o episódio bíblico da tentação e do pecado cometidos por Eva e Adão no Éden como ponto de partida para a construção do enquadramento mental que estabelecerá relações diferenciadas entre comida e gênero incorporadas por homens e mulheres ao longo de séculos da história ocidental.

Com efeito, o discurso acerca do pecado original constitui matriz fundadora, dentre outras coisas, da constituição $e$ significação dos papéis masculino e feminino no Ocidente medieval (Franco Júnior, 1992:113-139). É para ela que se deve voltar os olhos quando se pretende entender o processo pelo qual, durante tanto tempo, tais papéis encontraram-se necessariamente colados a dois respectivos suportes biológicos, os corpos de machos e fêmeas da espécie humana, os corpos de homens e mulheres. Assim, por terem sido engendradas na origem mítica da humanidade, as associações macho-homem-masculino e fêmeamulher-feminino são consideradas naturais (afinal "sempre foi assim") e, por isso, durante tanto tempo consideradas impossíveis de serem desfeitas. A familiaridade de Eva com a comida representada pelo fruto proibido - e sua administração para si $e$ para o outro estruturaram o horizonte teórico-discursivo sobre o qual, por séculos, foram sendo construídos modelos de comportamento alimentar distintos, porém considerados adequados às tríades macho-homem-masculino e fêmea-mulherfeminino. 
Há, contudo, outro aspecto a ser considerado nessa reflexão sobre o sistema de significação medieval das tríades acima mencionadas. Para Klapisch-Zuber (2002) é a criação e não a tentação no Paraíso que oferece elementos para a compreensão da natureza de Eva. Os relatos encontrados nos capítulos iniciais do Gênesis apresentam duas versões diferentes do momento da criação da humanidade. Uma primeira em que Deus cria o homem - entendido aqui como homem e mulher - à sua imagem e semelhança (Gênesis 1, 26-27); e uma segunda, em que Deus cria a mulher a partir da costela de Adão adormecido (Gênesis 2, 2124). Esta última versão será privilegiada pela exegese dos Pais da Igreja e é sobre ela que a teoria da inferioridade e consequente subordinação natural da mulher será elaborada e constantemente revisitada ao longo da história:

\begin{abstract}
Situando assim a origem da desigualdade fundamental dos sexos na diferença entre os momentos da criação dos corpos, a antropologia cristã qualificará como original $e$ superior a orientação da razão humana para a contemplação do divino, e como segunda e inferior sua orientação para as necessidades temporais. [...]. A Mulher que será objeto de tantas críticas [...], e o natural feminino que será alvo de tantas gozações, resultam destas assimilações da parte superior do humano - o espírito, a razão - com o masculino, e de sua parte inferior - os sentidos, e portanto, o corpo, a carne que a razão deveria controlar - com o feminino (Klapisch-Zuber, 2002:141).
\end{abstract}

Assim, por sua natureza inferior em entendimento $e$ racionalidade, Eva não consegue discernir as ameaças e perigos do fruto proibido e o oferece a Adão maculando e arruinando toda a humanidade. A familiaridade de Eva com a comida é, por conseguinte, algo da ordem do instintivo, do emocional, do impulsivo, do mágico, enfim, de tudo aquilo que se opõe à razão. Os saberes sobre a comida, de maneira alguma, referem-se a um conhecimento apreendido através do exercício do intelecto: ela os 
tem como uma marca, uma impressão digital, uma espécie de carga genética. Será, então, com facilidade e destreza que as descendentes de Eva, naturalmente feiticeiras, irão cultivar plantas, manipular ingredientes e se ocupar da cozinha, bem como utilizar o universo da comida como esfera de atuação feminina por excelência, tornando-o uma espécie de palco da existência.

Durante muito tempo não houve como conceber a desintegração dos elementos constitutivos daquelas tríades, ou seja, romper o elo entre os corpos de machos e fêmeas e seus atributos masculinos e femininos, julgados naturais. Foi preciso a instituição do pensamento secular e tecnocientífico, próprio à modernidade ( $e$ ainda mais à pós-modernidade) para colocar à prova o criacionismo e a matriz edênica e evocar a ruptura. Os sistemas de significação que organizavam rigidamente as velhas tríades se esgarçam $e$ as diferenças entre os corpos de machos $e$ fêmeas deixam de sinalizar automaticamente homens e mulheres ou sugerir necessariamente características masculinas e femininas.

Não obstante, não se pode negar que o processo de esfacelamento das antigas relações de gênero e substituição de seus fundamentos por uma nova matriz teórica ainda não foi totalmente completo. Prova disso, é o debate, ainda em pleno curso, acerca do papel que o corpo (com suas características físicas, químicas e biológicas) exerce na constituição dos seres humanos e sua subjetividade. $\mathrm{Na}$ sua configuração atual, a discussão procura romper com a polarização, até hoje recorrente, das propostas biologistas e sócio-culturalistas que enxergam, respectivamente, a prioridade da natureza bio-física ou dos fenômenos psicológicos e sócio-culturais na definição da natureza humana. Para o biologismo, o corpo é um organismo físico cujas interações causais são suficientes para explicar o mental; para o sócio-culturalismo, o corpo é uma junção de materiais (conteúdos) aos quais a comunidade atribui significado e organização (forma). Importante frisar que, em nenhum dos casos, o corpo deixa de ser objeto (Welton, 1998:1-8). 
É contra esse objetivismo, fundo comum para as duas perspectivas teóricas, que novas propostas têm se colocado. É o caso dos trabalhos acadêmicos que enxergam o corpo como sujeito-objeto no sentido que o termo "lived-body" sugere; ou seja, estudos que propõem que o entendimento da constituição do ser humano passe, necessariamente, pelo reconhecimento de que homens e mulheres existem/vivem em corpos que são, a um só tempo, biológicos, sociais e culturais. Na agenda desses novos trabalhos, a relação entre comida e gênero ainda não aparece explicitamente como objeto de estudo. Todavia, a investigação dos temas que lhes são caros $^{2}$ certamente auxiliará a compreendêla de modo mais aprofundado (Welton, 1998).

É possível que essa nova perspectiva teórica permita, dentre outras coisas, que se argumente com mais propriedade acerca das motivações que levam a tríade fêmea-mulher-feminino a permanecer calcada em noções tradicionais tais como aquelas de matriz edênica. "Comer como um passarinho" e "cozinhar como uma feiticeira" metamorfosearam-se e ganharam novas roupagens $e$, de alguma maneira, ainda ecoam como referências de comportamento feminino contemporâneo; referências expressas em um programa que prega, acima de tudo, a beleza. Ora, ser bela é ser magra, o que no imaginário popular pode ser atingido comendo pouco e não equilibradamente como prega o discurso médico sobre a saúde. Ser bela é igualmente ser capaz de exercer livremente e sem culpa a sedução e a fruição de prazeres dentre os quais o gastronômico conquista cada vez mais espaço. Em suma, um programa que apesar de contemporâneo em suas proposições revela, a despeito de valores caros às sociedades contemporâneas

2 Don Welton, na Introdução de sua antologia que reúne trabalhos de filósofos, sociólogos e psicólogos, menciona as seguintes temáticas: o lugar dos padrões de ação biologicamente estabelecidos na constituição do corpo; a constituição da sensibilidade e a materialidade dos corpos; as estruturas do corpo como possíveis "inscrições"; a relação entre tipos diferentes de experiências corporais; a distinção de comportamentos em corpos femininos e masculinos; a questão da identidade do gênero (Welton, 1998:4). 
como a autonomia e o poder de escolha, que o feminino parece não ter conseguido se desprender totalmente de referências herdadas das origens míticas da história ocidental.

\section{Referências bibliográficas}

BEL, Rudolph. Holy Anorexia. Chicago, University of Chicago Press, 1985.

Bynum, Caroline. Holy feast and holy fast. Berkeley, University of California Press, 1987.

FLANDRIN, Jean-Louis. A distinção pelo gosto. In: ARIÈS, Philippe; DUBY, Georges. (orgs.) História da vida privada, vol.3. São Paulo, Cia. das Letras, 1991, pp.267-309.

FRANCO JÚNIOR, Hilário. As utopias medievais. São Paulo, Brasiliense, 1992.

GarCíA, Yuliuva. Acerca del género como categoría analítica. Nómadas. Revista Crítica de Ciencias Sociales y Jurídicas (13), Madrid, Universidad Complutense de Madrid, 2006. Disponível em $<$ http://portal.ucm.es/web > - acesso em 20 jan. 2012.

KLAPISCH-ZUBER, Christiane. Masculino/feminino. In: LE GOFF, Jacques; SchMITT, Jean-Claude. (orgs.) Dicionário Temático do Ocidente Medieval. Bauru, Edusc/São Paulo, Imprensa Oficial do Estado, 2002, pp.137-149.

PORTER, Roy. História do corpo. In: BuRKe, Peter. (org.) A escrita da história. Novas perspectivas. São Paulo, Unesp, 1991, pp.291-326.

SILVA, Andréia Cristina Lopes Frazão da. Aproximações historiográficas ao medievo: teoria, métodos e técnicas da história das mulheres e dos estudos de gênero. In: ZIERER, Adriana; XIMENDES, Carlos Alberto. (orgs.) História antiga e medieval. Cultura e Ensino. São Luís, Editora UEMA, 2009, pp.91-105.

Welton, Donn. (ed.) Body and Flesh. A Philosophical reader. Oxford, Blackwell, 1998. 